\title{
RAEDER'S SYNDROME AFTER EMBOLIZATION OF A GIANT INTRACAVERNOUS CAROTID ARTERY ANEURYSM
}

\section{Pathophysiological considerations}

\author{
Claudio Esteves Tatsui", Daniel Monte-Serrat Prevedello², Andrei Koerbel', \\ Joacir Graciolli Cordeiro², Leo Fernando da Silva Ditzel1', Joao Candido Araujo3
}

\begin{abstract}
We present the case of a 47 years old woman submitted to an endovascular trapping of a left cavernous internal carotid artery aneurysm, in which the distal balloon was inflated, as usually done, within the cavernous segment of the internal carotid artery, diffe rent from the proximal one which was inflated inside the carotid canal due to technical problems. Consequently, a clinical picture of Raeder's paratrigeminal neuralgia took place. This is the first case report in the literature with theses characteristics. A review of the anatomic pathways and further considerations about the possible pathophysiological mechanisms involved are presented.
\end{abstract}

KEY WORDS: Raeder's paratrigeminal neuralgia, headache, cephalalgia, neuroendovascular procedures.

\begin{abstract}
Sín drome de Raeder após embolização de aneurisma gigante de artéria carótida intracavernosa: considerações fisiopatológicas

RESUMO - Apresentamos o caso de uma mulher de 47 anos submetida a obliteração endovascular de um aneurisma gigante de carótida interna cavernosa à esquerda, no qual o balão distal foi inflado, tal como usual, dentro do segmento cavernoso da artéria carótida interna, diferente do proximal, o qual foi inflado dentro do canal carotídeo devido a problemas técnicos. Conseqüentemente, um quadro clínico de neuralgia paratrigeminal de Raeder se instalou. Este é o primeiro relato na literatura com estas características. Uma revisão das vias anatômicas e maiores considerações a respeito de possíveis mecanismos fisiopatológicos envolvidos são apresentados.
\end{abstract}

PALAVRAS-CHAVE: neuralgia paratrigeminal de Raeder, cefaléia, procedimentos neuroendovasculares.

Oculosympathetic paresis associated with ipsilateral continuous head pain was first described by a Norwegian neurologist, J.G. Raeder, in 1918 $18^{1-3}$. In the author's original reports, a skull base infiltrative neoplasm in the middle cranial fossa, close to the petrous apex and Gasserian ganglion, caused the symptoms ${ }^{1}$. Raeder's paratrigeminal neuralgia became a frequently used terminology at that time, correlating, after autopsy cases, the symptoms described by Raeder to expanding lesions involving the cavernous sinus and structures adjacent to the trigeminal branches. The picture consisting of orbital pain plus oculosympathetic palsy (ptosis and miosis) had, in consequence, an important clinical localizing value before the development of modern imaging methods. Advances in microneurosurgeryand better understanding of the microanatomy of the cavernous sinus ${ }^{4,5}$, petrous ape ${ }^{6,7}$, orbit ${ }^{8}$ and infratemporal fossa ${ }^{9}$, associated with the introduction of modern staining techniques, retrograde axonal mapping ${ }^{10,11}$ and immunocytochemistry ${ }^{12}$ yielded more complete in formation about the skull base innervation and its relation with pathophysiologic events involved in the genesis of Raeder's neuralgia.

We report a case of a woman submitted to an endovascular trapping of a giant aneurysm of the left cavernous sinus with detachable balloons, who immediately after the procedure developed a classic presentation of ipsilateral Raeder's neuralgia. Balloon inflation inside the carotid canal is proposed as the pathophysiological mechanism, through

Department of Neurosurgery - Hospital Nossa Senhora das Graças, Curitiba PR, Brazil: ${ }^{1}$ Neurosurgeon; ${ }^{2}$ Resident in Neurosurgery; ${ }^{3}$ Neurosurgeon Chief of the Residency Program.

Received 5 November 2004, received in final form 21 December 2004. Accepted 12 March 2005.

Dr. Daniel Monte Serrat Prevedello - Rua Alcides Munhoz 433 - 80810-040 Curitiba PR - Brasil. E-mail: prevedello@hotmail.com 


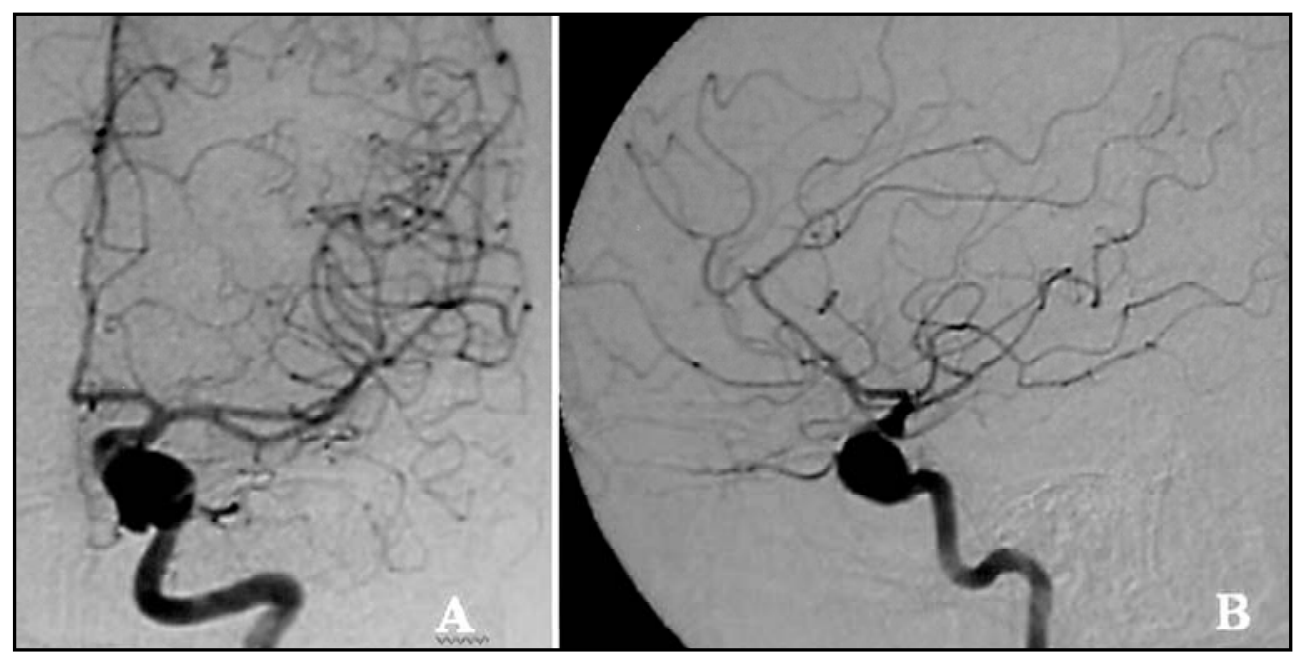

Fig 1. Angiography showing a giant aneurysm of the cavernous segment of the left internal carotid artery. A) frontal view. B) side view.

damaging of the left internal carotid artery in the petrous segment, leading to Raeder's syndrome.

\section{CASE}

A 47 years old woman presented incapacitating vertigo with no other symptom. Magnetic resonance imaging (MRI) revealed a left paraselar-expanding lesion demonstrated by angiography to be a giant aneurysm of the cavernous segment of the left internal carotid a rt e ry (Fig 1). Occlusion tests of left internal carotid arteryshowed absence of neurological deficits and a good crossover perfusion through anastomoses of the circle of Willis.

One week after the diagnosis, an endovascular trapping of the cavernous segment of the left internal carotid with detachable balloons, under general anesthesia, was accomplished. The proximal balloon had to be positioned at the level of the carotid canal, due to technical difficulties in placing it closer to the lesion. Flow absence within the aneurysm and patency of collateral circulation were again confirmed before ending the procedure.

Immediately after the procedure the patient referred intense pain around the left periorbital area and deep face in relation to the nasal fossa. The pain persisted in spite of appropriate medication, reaching degree 9 in the analogical visual scale for pain ${ }^{13,14}$. In addition to pain, she had ptosis of the left superior eyelid and miosis of the left pupil, which was brought out by darkening the room, leading the right normal pupil to dilate. There was no deficit of the extraocular motor system and the facial and trigeminal nerves were clinically intact. Pharmacologic testing with $1 \%$ hydroxyampheta mine confirmed the lesion to be postganglionic, causing no dilation of the left pupil.

A new MRI and angiography (Fig 2) demonstrated

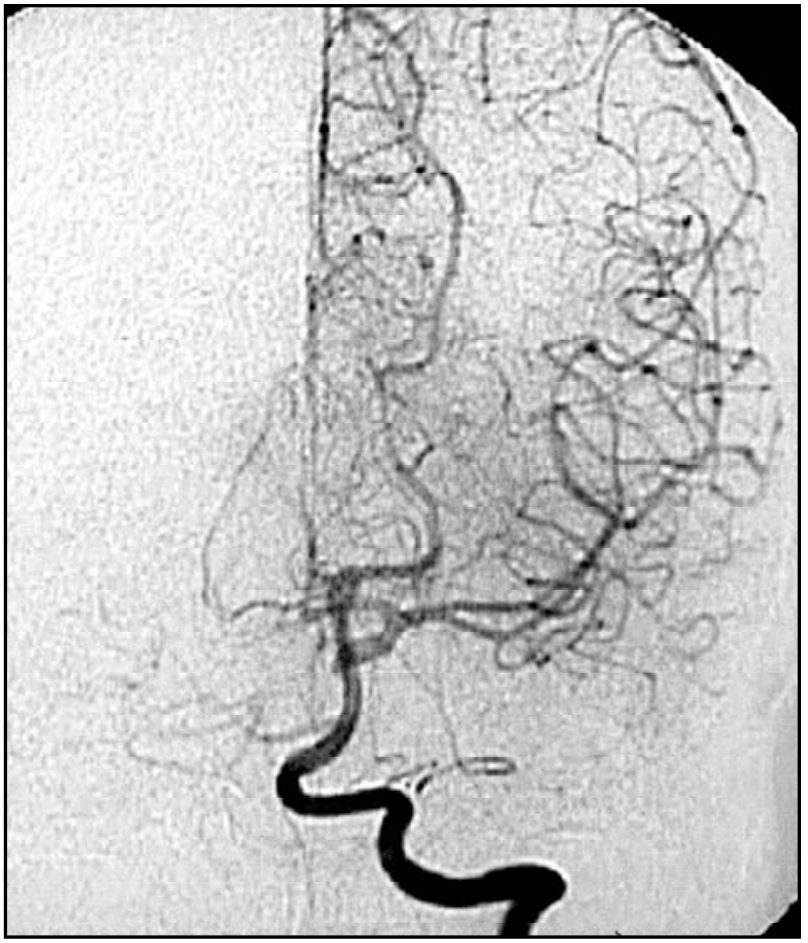

Fig 2. Angiography demonstrating the thrombosed aneurysm inside the left cavernous sinus and a good perfusion of the ipsi lateral hemisphere through posterior circulation, after an endo vascular trapping of the cavernous segment of the left inter nal carotid artery with detachable balloons.

a thrombosed aneurysm inside the left cavernous sinus without any increase in its volume comparing to the pre operative exam and a good perfusion of the ipsilateral hemisphere through posterior circulation. No associated lesion could be demonstrated.

Pain and oculosympathetic paresis remained unchanged for exactly two months. Subsequently, sings and symptoms pro g ressively subsided up to a normal clini- 
cal picture. Two years after the procedure she is assymptomatic. The patient signed the informed consent for this publication.

\section{DISCUSSION}

Immunocytochemical studies accomplished in laboratoryanimals and in preparations of human cerebral arteries demonstrated the presence of ne rve terminals containing neuropeptides within the wall of the human cerebral arteries ${ }^{15,16}$. Neuropeptides such as vasoactive intestinal polypeptide (VIP), marker of parasympathetic nerves, calcitonin gene-related peptide (CGRP), substance $P(S P)$, marker of trigeminal nerves, and neurokinin $A$, were demonstrated ${ }^{17,18}$. It is believed that these neuropeptides, present in large vessels and capillaries, a re related to an integrated system with a substantial role in cerebral blood flow autoregulation under normal and pathological conditions ${ }^{15}$. Experimental evidence demonstrates the vascular reactivity under the action of these modulators ${ }^{19}$.

Retrograde axonal mapping in laboratory shows that most of these fibers originate from the trigeminal ganglion, while other studies demonstrate that the stimulation of structures innervated by these terminations causes the expression of gene $c-f o s$, marker of neuronal activation, in the neurons of the spinal trigeminal nucleus ${ }^{20}$, there fore demonstrating that these fibers are trigeminal aff e rents in nature. These mechanisms are part of what Moskowitz denominated trigeminovascular system ${ }^{20}$.

Scientific evidence suggests that such innervations are present in humans and they would be involved in the pathophysiology of headaches. A mechanism of central activation is postulated, with antidromic conduction, in which neuropeptides a re delivered on terminals of the trigeminovascular system, leading to an aseptic neurogenic inflammation. Subsequently, through anterograde conduction mechanisms there would be an activation of trigeminal projections to the thalamus, resulting in perception of the painful sensation in the specific head segment ${ }^{21}$.

Internal carotid art e ry is subdivided into several segments. One of them, the petrous segment, crosses through the temporal bone inside the $c$ a rotid canal, where a bony framework intimately wraps it up ${ }^{22}$. In the same way, sympathetic fibers are found inside the carotid canal, lying on the surface of the internal carotid artery ${ }^{23}$.
The sympathetic stimuli destined to cranial segment originate within the hypothalamus and follow a specific pathway through the brain stem and spinal cord to synapse with preganglionic cells within the intermediolateral gray matter of the upper thoracic segments, $\mathrm{T} 1$ to $\mathrm{T}^{24}$. Preganglionic fibers exit the spinal cord through the white rami communicantes from the ventral root at the segmental level at which their cells bodies are located and establish synapses with postganglionic neurons, often distributed among diffe rent paravertebral ganglia. The axons of postganglionic neurons within the paravertebral ganglia exit through the gray rami communicantes, and those which innervate structures inside the head travel along branches of the carotid arteries to their targets ${ }^{25}$. Postganglionic sympathetic fibers assemble in a network around the common carotid artery and follow its branches. Following the bifurcation, fibers along branches of external carotid art e rybring sympathetic innervation to the sweat glands, erector pili muscles and subcutaneous capillary blood vessels of the face. Intemally, within the carotid canal, some postganglionic fibers organize to form the deep petrosal nerve, which gives sympathetic innervation mainly to the lacrimal gland ${ }^{25}$. The cave rnous segment of the internal carotid artery contains postganglionic fibers which send efferents that follow the abducens, trochlear and oculomotor nerves and the ophthalmic artery itself. Ultimately they get to the ciliary ganglion and long cili a rynerves ${ }^{1,23}$ to reach the pupillary dilator muscle and tarsal muscle of Muller ${ }^{26}$.

The cell bodies of the preganglionic neurons of the parasympathetic system are located within the brain stem and in segments S2 to S4 of the spinal cord. Parasympathetic preganglionic nuclei to the head include the Edinger-Westphal nucleus and superior and inferior salivary nuclei. The orbit receives parasympathetic effe rents from the Edinger-Westphal and from the superior salivary nuclei. The inferior salivary nucleus sends fibers to the parotid gland ${ }^{27,28}$.

The nervus intermedius of the facial nerve contains fibers from the superior salivary nucleus, which synapse in the pterygopalatine and submandibular ganglia to innervate the lacrimal gland and submandibular-sublingual glands respective$l^{27,28}$. The great petrosal nerve arises from the facial nerve at the geniculate ganglion and passes medially through the petrous temporal bone 


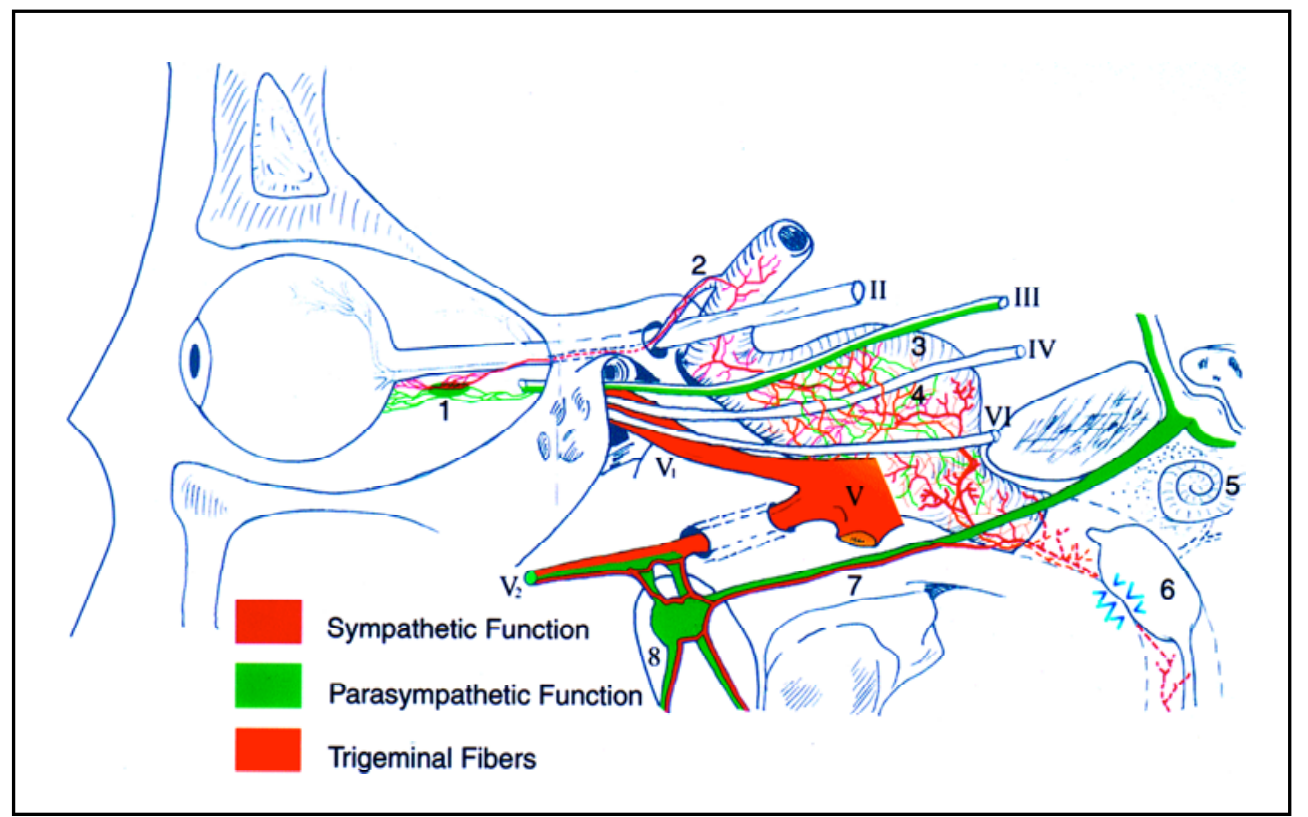

Fig 3. Anatomical illustration demonstrating sympathetic, parasympathetic and trigeminal fibers at the skull base generating the lateral sellar nerve plexus. 1) Ciliary ganglion; 2) Ophthalmic artery; 3) Aneurysm of the cavernous segment of the internal carotid artery; 4) Lateral sellar nerve plexus; 5) Cochlea next to the facial nerve (VII); 6) Detachable balloon; 7) Nerve of the pterygoid canal; 8) pterygopalatine ganglion; II, III, IV, V (V1, V2, V3), VI - cranial nerves.

to lie in a groove on its anterior surface beneath the temporal lobe and dura of the middle cranial fossa. It runs beneath the trigeminal ganglion, ante romedially across the foramen lacerum. There, it is joined by the deep petrous nerve (sympathetic) and becomes the nerve of the pterygoid canal. It passes through the pterygopalatine fossa to enter the posterior aspect of the pterygopalatine ganglion. Fibers are then distributed with branches of the maxillary division mainly through the zygomatic-orbital nerve, which terminates on the lateral orbital wall to the lacrimal gland ${ }^{6}$.

Edinger-Westphal nucleus sends fibers that integrate the oculomotor nerve, which after passing through the cavernous sinus enters the orbit th rough the superior orbital fissure and splits into superior and inferior divisions. The inferior division gives rise to the inferior oblique nerve, which ca rries the general visceral motor fibers (parasympathetic) to the ciliary ganglion. Short ciliary nerves, from the ganglion, innervate the ciliary body, sphincter pupillae and uveal tract glands ${ }^{27,28}$.

All three systems described above (sympathetic, parasympathetic and trigeminovascular) generate a rich nervous plexus located in the lateral wall of the cavernous sinus, the so called "lateral sellar nerve plexus", demonstrated by Bleys et al. ${ }^{29}$.
Anastomoses between the lateral sellar plexus and fibers from the Gasserian ganglion carry trigeminal somatic afferent fibers along the wall of the internal carotid arteries. These connections are responsible for the conduction of nociceptive sensation mainly from petrous, lacerum and cavernous segments. Multiple anastomoses from the lateral sellar plexus, connected to the sympathetic carotid nerves and fibers coming from the pterygopalatine ganglion form a mixed plexus with sympathetic, parasympathetic and affe rent somatic fibers ${ }^{29}$. Alterations in the venous drainage of the cavernous sinus triggered by an activation of the trigeminovascular system (related to the lateral sellar plexus inside the cavernous sinus) may cause peri$c$ a rotid aseptic neurogenic inflammation, playing an important role in the genesis of pain and oculosympathetic dysfunction in attacks of cluster-type migraine ${ }^{30}$.

It is postulated, in the present case, that placement of a proximal balloon at the level of the carotid canal caused compression of sympathetic nerves located around the internal carotid arteryagainst the bony wall of the carotid canal, causing sympathetic dysfunction, as well as activation of nociceptive terminals from the trigeminovascular system (Fig 3). Connections between such structu- 
res and affe rent convergents to the spinal trigeminal nucleus ${ }^{31}$ would account for pain referred to the ipsilateral periorbital area.

Pain in the trigeminal area occurs in the absence of sensory deficit, because trigeminal fibers from the ophthalmic division are not affected by the pathological process. Parasympathetic function is also preserved, considering that visceral efferents to the pupils travel along the oculomotor nerve, originally spared in this process. The pain irradiated to the deep facial area, inferior portion of the orbit and nasal fossa may occur due to the already mentioned connections between the lateral sellar plexus and the pterygopalatine ganglion ${ }^{29}$. Relief obtained after anesthetic blockade of the ganglion for certain types of headache, such as cluster-like migrane, may be explainned by a possible reduction of input to the trigeminovascular system and its connections ${ }^{32}$.

In conclusion, this reportsupports Bley's observations, which identified a nerve plexus in relation to the internal carotid artery wall, with afferent innervation from trigeminal fibers ${ }^{29}$. Multiple connections between sympathetic and parasympathetic systems may explain the character of pain i rradiation when these nerve fibers are stimulated. Furthermore, Raeder's neuralgia would correspond to a clinical manifestation of a dysfunction in the trigeminovascular system involving the internal carotid artery and multiple connections of the lateral sellar plexus in the cavernous sinus.

Acknowledgement - We thank the medical student, Endrigo Monte Serrat Prevedello for contributing with a didactic illustration to this manuscript (Fig 3).

\section{REFERENCES}

1. Goadsby PJ. Raeder's syndrome: paratrigeminal paralysis of the oculopillary sympathetic system. J Neurol Neuro s u rg Psychiatry 2002; 72:297-299.

2. Solomon S, Lustig JP. Benign Raeder's syndrome is probably a manifestation of carotid artery disease. Cephalalgia 2001;21:1-11.

3. Salvesen R. Raeder's syndrome. Cephalalgia 1999;19(Suppl 25)S42-S45

4. Rhoton AL Jr, Inoue T. Microsurgical approaches to the cavernous sinus. Clin Neurosurg 1991;37:391-439.

5. Rhoton A L Jr, Hardy DG, Chambers SM. Microsurgical anatomy and dissection of the sphenoid bone, cavernous sinus and sellar region. Surg Neurol 1979;12:63-104.

6. Rhoton AL Jr. The anterior and middle cranial base. Neurosurgery 2002;51(Suppl 4)S273-S302.
7. Rhoton AL Jr. The temporal bone and transtemporal approaches. Neurosurgery 2000;47 (Suppl 3)S211-S265.

8. Rhoton AL Jr. The orbit. Neurosurgery 2002;51(Suppl 4)S303-S334.

9. Hitotsumatsu T, Rhoton AL Jr. Unilateral upper and lower subtotal maxillectomy approaches to the cranial base: microsurgical anatomy. Neurosurgery 2000;46:1416-1452.

10. Edvinsson L, Hara H, Uddman R. Retrograde tracing of nerve fibers to the rat middle cerebral artery with true blue: colocalization with different peptides. J Cer Blood Flow Metab 1989;9:212-218.

11. Liu-Chen LY, Gillespie SA, NorregaardTV, Moskowitz MA. Co-localization of retrogradely transported wheat germ agglutinin and the putative neurotransmitter substance $\mathrm{P}$ within trigeminal ganglion cells projecting to cat middle cerebral artery. J Comp Neurol 1984;225:187-192.

12. Liu-Chen LY, Mayberg MR, Moskowitz MA. Immunohistochemical evidence for a substance P-containing trigeminovascular pathway to pial arteries in cats. Brain Res 1983;268:162-166.

13. Scott PJ, Huskisson EC. Measurement of functional capacity with visual analogue scales. Rheumatol Rehab 1977;16:257-258.

14. Piovesan EJ, Lange MC, Werneck LC, Kowacs PA, Piovesan LM. Comparative study between visual analogue scale (VAS) and tactile analogue scale (TAS), a new scale. Cephalalgia 2000;20:323.

15. Buki A, Horvath Z, Kallo I, Liposits Z, Lengvari I, Doczi TP. Peptidergic innervation of human cerebral blood vessels and saccular aneurysms. Acta Neuropathol (Berl) 1999;98:383-388.

16. Edvinsson L, Jansen I, Cunha e Sa M, Gulbenkian S. Demonstration of neuropeptide containing nerves and vasomotor responses to perivascular peptides in human cerebral arteries. Cephalalgia 1994;14:88-96.

17. Edvinsson L. Sensory nerves in man and their role in primary headaches. Cephalalgia 2001;21:761-764.

18. Edvinsson L, Goadsby PJ. Neuropeptides in the cerebral circulation: relevance to headache. Cephalalgia 1995;15:272-276.

19. Edvinsson L, Jansen Olesen I, Kingman TA, McCulloch J, Uddman R. Modification of vasoconstrictor responses in cerebral blood vessels by lesioning of the trigeminal nerve: possible involvement of CGRP. Cephalalgia 1995;15:373-383.

20. Moskowitz MA. Trigeminovascular system. Cephalalgia 1992;12:127.

21. Moskowitz MA. The trigeminovascular system. In Olesen J, (ed). The headaches. New York: Raven Press, 1993:97-104.

22. Bouthillier A, van Loveren HR, Keller JT. Segments of the internal carotid artery: a new classification. Neurosurgery 1996;38:425-433.

23. Von Overbeeke JJ, Dujovny M, Dragovic L, Ausman JI. Anatomy of the sympathetic pathways in the carotid canal. Neurosurgery 1991;29: 838-843.

24. Loewy AD, Araujo JC, Kerr FW. Pupillodilator pathways in the brain stem of the cat: anatomical and electrophysiological identification of a central autonomic pathway. Brain Res 1973;60:65-91.

25. Von Overbeeke JJ, Dujovny M, Dragovic L, Ausman JI. Anatomy of the sympathetic pathways in the carotid canal. Neurosurgery 1991;29:838843.

26. Ruskell GL. Accommodation and the nerve pathway to the ciliary muscle: a review. Ophthalmic Physiol Opt 1990;10:239-242.

27. Ruskell GL. The orbital branches of the pterygopalatine ganglion and their relationship with internal carotid nerve branches in primates. J Anat 1970;106:323-339.

28. Ruskell GL. Orbital passage of pterygopalatine ganglion efferents to paranasal sinuses and nasal mucosa in man. Cells Tissues Organs 2003; 175:223-228.

29. Bleys RLAW, Janssen LM, Groen GJ. The lateral sellar nerve plexus and its connections in humans. J Neurosurg 2001;95:102-110.

30. Dodick DW, Rozen TD, Goadsby PJ, Silberstein SD. Cluster headache. Cephalalgia 2000;20:787-803.

31. Piovesan EJ, Kowacs PA, Tatsui CE, Lange MC, Ribas LC, Werneck LC. Refer red pain after painful stimulation of the greater occipital nerve in humans: evidence of convergence of cervical aff e rences on trigeminal nuclei. Cephalalgia 2001;21:107-109.

32. Maizels M, Geiger AM. Intranasal lidocaine for migraine: a randomized trial and open-label follow-up. Headache 1999;39:543-551. 